\title{
A prospective study of patients with CT detected pallidal calcifications
}

\author{
G Fénelon, F Gray, F Paillard, M Thibierge, F Mahieux, A Guillard
}

\begin{abstract}
In a prospective study pallidal calcification was detected in 30 of $1478(2 \%)$ adult patients, on CT brain scans. In 8 cases $(26 \%)$, the calcifications were detected either years after, or during the course of, conditions known to cause basal ganglia calcification, including AIDS in four cases. Eight patients (three with AIDS) had disturbances of calcium and phosphorus metabolism. It was concluded that: a) pallidal calcification is not uncommon and aetiological factors may be recognised more often than previously reported; b) AIDS is emerging as a significant cause of pallidal calcification in young adults, and c) in AIDS and other conditions, abnormal calcium and phosphate metabolism may act in conjunction with local vascular changes.
\end{abstract}

$(F$ Neurol Neurosurg Psychiatry 1993;56:622-625)

With the increased availability of CT, the incidental discovery of pallidal calcifications has become more frequent. The significance of such calcifications is unclear, but some authors claim that those confined to the pallidum should be considered as "physiological" in subjects over the age of 40 years. $^{1}$ However, the list of conditions associated with basal ganglia calcifications, whether limited to the pallidum or not, is expanding.

Service des maladies du système nerveux, Hôpital Tenon, Paris, France

G Fénelon

F Mahieux

A Guillard

Départment de

pathologie

(neuropathologie),

Hôpital Henri

Mondor, Créteil

F Gray

Service d'explorations fonctionnelles, Hôpital Tenon, Paris F Paillard

Service de radiologie, Hôpital Tenon, Paris France

$M$ Thibierge

Correspondence to: Dr Fénelon, Service des maladies du système nerveux, Hôpital Tenon, 4 rue de la Chine, 75020 Paris, France.

Received 13 January 1992 and in revised form 1 april 1992 Accepted 16 July 1992

The aim of this prospective study was to assess the prevalence and clinical significance of pallidal calcification in a population of patients in our hospital having CT.

\section{Patients and methods}

All inpatients and outpatients who had CT of the brain during a 16 month period were included in this study.

CT was performed using either a CGR CE 10000 or a Siemens Somatom Dr. All scans were assessed by the same neuroradiologist (MT). Hyperdensity of pallidal areas was identified visually and measured.

All patients with CT detected pallidal calcifications were interviewed and examined by one of us (GF); the records were reviewed with the patients' informed consent. Certain conditions (past or present) were systematically investigated, that is, endocrine and metabolic diseases, exposure to toxic sub- stances (including lead), carbon monoxide poisoning, anoxia, CNS infection and cranial irradiation. Long term treatments and family histories were also recorded.

Serum levels of calcium and phosphorus were measured at least twice. Abnormal levels prompted further investigations, including calcium and phosphate excretion, parathormone (PTH) levels (radio-immunological assay), nephrogenic cyclic AMP (that is cAMP secreted by the tubule under the influence of PTH), and another index of PTH activity, the renal threshold phosphate concentration.

Post mortem examination, performed in two cases (6 and 15), was restricted to the brain. Gross examinations were made on coronal sections of the cerebral hemispheres and on sections of the cerebellum and the brainstem perpendicular to its axis. Tissue blocks were embedded in paraffin wax. Thick slices of each cerebral hemisphere and the cerebellum/brainstem were embedded in celloidin. Sections were stained with haematoxylin and eosin, the Loyez method for myelin, Bodian silver impregnation combined with Luxol fast blue, periodic acid Schiff (PAS), Perl's method (Prussian blue) for iron and the Von Kossa method for calcium. Paraffin sections were immunostained for HIV detection using an indirect method with immunoalkaline phosphatase and monoclonal antibodies against p24 and p17 (DuPont).

\section{Results}

Thirty patients $(2.03 \%)$ with pallidal calcifications were identified among 1478 patients who had CT of the brain. There were 20 women and 10 men, with a mean age of 60.3 years (range: 31-90). Only seven of the thirty patients were under fifty years of age. None had clinical features indicating basal ganglia dysfunction, such as a Parkinsonian syndrome or dyskinesias of any type. The indications for CT varied greatly, the most frequent $(n=7)$ being a suspicion of cerebral ischaemia. The pallidal calcification was detected incidentally in all cases. It was bilateral in 25 cases and unilateral in 5; there was associated calcification of the head of the caudate nucleus in two instances, and the dentate nucleus in one case. Skull radiographs, obtained in 26 cases, showed calcification in only one.

A condition (past or present) known to be 
Table 1 Cases with a possible cause for the basal ganglia calcifications or disturbances in phosphorus/calcium metabolism

\begin{tabular}{|c|c|c|c|c|c|}
\hline $\begin{array}{l}\text { Case } \\
\text { Numbers }\end{array}$ & $\begin{array}{l}\text { Sex, } \\
\text { age }\end{array}$ & $\begin{array}{l}\text { Indication } \\
\text { for } C T\end{array}$ & Associated conditions & $\begin{array}{l}\text { Phospho-calcic metabolism } \\
\text { disturbance }\end{array}$ & $\begin{array}{l}\text { Possible cause for } \\
\text { calcifications }\end{array}$ \\
\hline $\begin{array}{l}1 \\
2\end{array}$ & $\begin{array}{l}\text { F, } 61 \\
F, 66\end{array}$ & $\begin{array}{l}\text { Diplopia } \\
\text { Headache, depression }\end{array}$ & $\begin{array}{l}\text { Breast cancer } \\
-\end{array}$ & $\begin{array}{l}\text { Cancer associated hypercalcaemia } \\
\text { - }\end{array}$ & $\begin{array}{l}\text { Carbon monoxide } \\
\text { intoxication } \\
\text { (at age } 36)\end{array}$ \\
\hline 3 & F, 69 & $\begin{array}{l}\text { Suspicion of neoplasia } \\
\text { Search for metastases }\end{array}$ & $\begin{array}{l}\text { Renal failure, hypertension, } \\
\text { diabetes }\end{array}$ & Secondary hyperparathyroidism & - \\
\hline 5 & $F, 86$ & $\begin{array}{l}\text { Internuclear } \\
\text { ophthalmoplegia }\end{array}$ & $\begin{array}{l}\text { Hypertension, diabetes, ischaemic stroke, } \\
\text { parathyroid adenoma }\end{array}$ & Primary hyperparathyroidism & $\begin{array}{l}\text { Primary hyper PTH } \\
\text { (known for } 6 \text { years) }\end{array}$ \\
\hline 6 & M, 41 & $\begin{array}{l}\text { Behavioural } \\
\text { disturbances }\end{array}$ & $\begin{array}{l}\text { AIDS, glomerulosclerosis with renal } \\
\text { failure, mild intellectual } \\
\text { impairment }\end{array}$ & Secondary hyperparathyroidism & AIDS \\
\hline 7 & $\mathbf{M}, 34$ & Fever & AIDS, pneumocystis carinii pneumonia & $\begin{array}{l}\text { Isolated hyperphosphatemia } \\
\text { (metabolic investigation } \\
\text { incomplete) }\end{array}$ & AIDS \\
\hline 8 & F, 64 & Seizures & - & - & $\begin{array}{l}\text { Tuberculous meningitis } \\
\text { coma (at age } 35 \text { ) }\end{array}$ \\
\hline 12 & F, 76 & $\begin{array}{l}\text { Transient ischaemic } \\
\text { attacks }\end{array}$ & $\begin{array}{l}\text { Ischaemic stroke, osteoporosis, intermittent } \\
\text { treatment with calcium, phosphorus } \\
\text { and calcitonin }\end{array}$ & $\begin{array}{l}\text { Hypercalcaemia with } \\
\text { hypercalciuria }\end{array}$ & - \\
\hline 15 & M, 36 & $\begin{array}{l}\text { Cerebral toxoplasmosis } \\
\text { (follow up) }\end{array}$ & $\begin{array}{l}\text { AIDS, pulmonary tuberculosis, } \\
\text { toxoplasmosis of the brain, progressive } \\
\text { multifocal leukoencephalopathy }\end{array}$ & $\begin{array}{l}\text { Pseudohypoparathyroidism or } \\
\text { mild hypoparathyroidism }\end{array}$ & AIDS \\
\hline 20 & M, 55 & Intellectual impairment & - & Sosondar- & $\begin{array}{l}\text { Tuberculous meningitis } \\
\text { (at age } 36 \text { ) }\end{array}$ \\
\hline 29 & $\mathbf{M}, 31$ & $\begin{array}{l}\text { Cerebral toxoplasmosis } \\
\text { (follow up) }\end{array}$ & $\begin{array}{l}\text { AIDS, toxoplasmosis of the brain, } \\
\text { intellectual impairment, renal } \\
\text { failure }\end{array}$ & Secondary hyperparathyroidism & AIDS \\
\hline
\end{tabular}
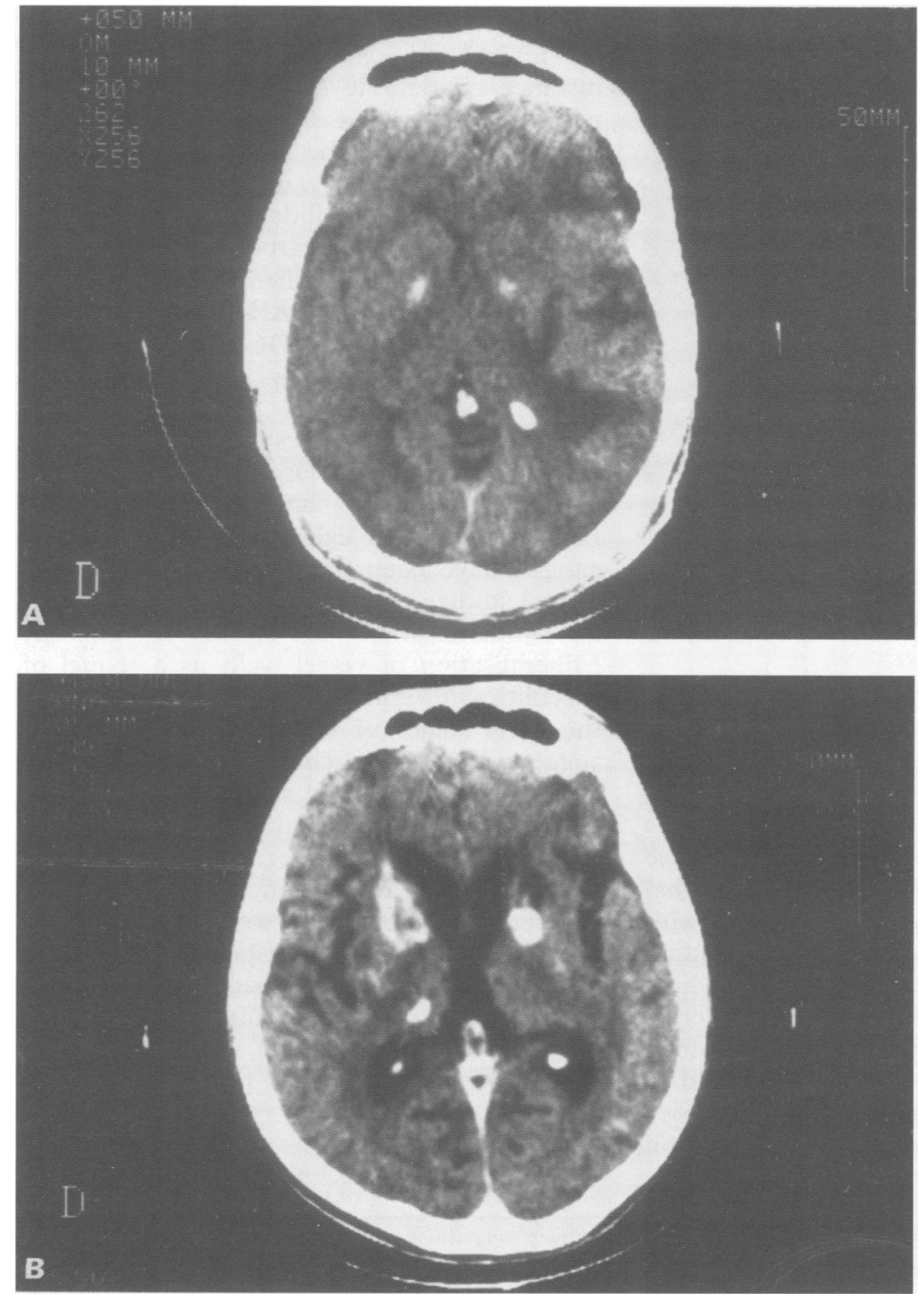

Figure 1 CT scans without contrast injection in two patients with AIDS; A) Patient 15 (36 year old man). Calcifications are small, confined to the pallidal area, bilateral and symmetrical (the hypodense areas in the left hemisphere are due to toxoplasmosis abscess); B) Patient 29 (31 year man). Bilateral and asymmetrical calcifications involving the basal ganglia and the right thalamus. Calcifications were detected in the follow up of treatment for cerebral toxoplasmosis. occasionally associated with basal ganglia calcifications was found in eight cases (table 1). The patient with primary hyperparathyroidism (case 5) had had a parathyroid adenoma for 7 years but had persistently declined surgical treatment. Four patients $(6$, $7,15,29)$ had the acquired immunodeficiency syndrome (AIDS) (table 1). The calcifications were symmetrical and confined to the pallidal area in three cases (fig 1A). In another patient (29), the calcifications were asymmetrical and diffuse, extending into both the lenticular and caudate nuclei, the right thalamus and the hemispheric white matter (fig 1B). These calcifications developed within a few months while the patient was being treated for multiple brain abcesses due to toxoplasmosis.

Three patients could not be investigated according to the protocol: one left the area (case 7), one died shortly after CT (case 19) and one declined further investigation (case 27). A disturbance of phosphate/calcium metabolism was found in eight cases (table 1) which included the four patients with AIDS. Two patients (6 and 29) had renal failure with secondary hyperparathyroidism; one (case 7) had an elevated serum phosphate level but could not be investigated further; in the last case (15), we could not distinguish between mild hypoparathyroidism and pseudohypoparathyroidism on the basis of the available data.

Neuropathological investigation of two AIDS patients revealed similar changes. The mineral deposits mainly involved the vessel walls, consisting either of extensive mineralisation of thickened arteriolar walls, or of smaller globular deposits around capillaries. These deposits appeared dark purple in sections stained with haematoxylin and eosin, were PAS-positive, and also stained positively for iron (Perl's method) and calcium (von Kossa's method). Vascular mineralisation was bilateral and symmetrical, and predominantly involved the basal ganglia, especially the 

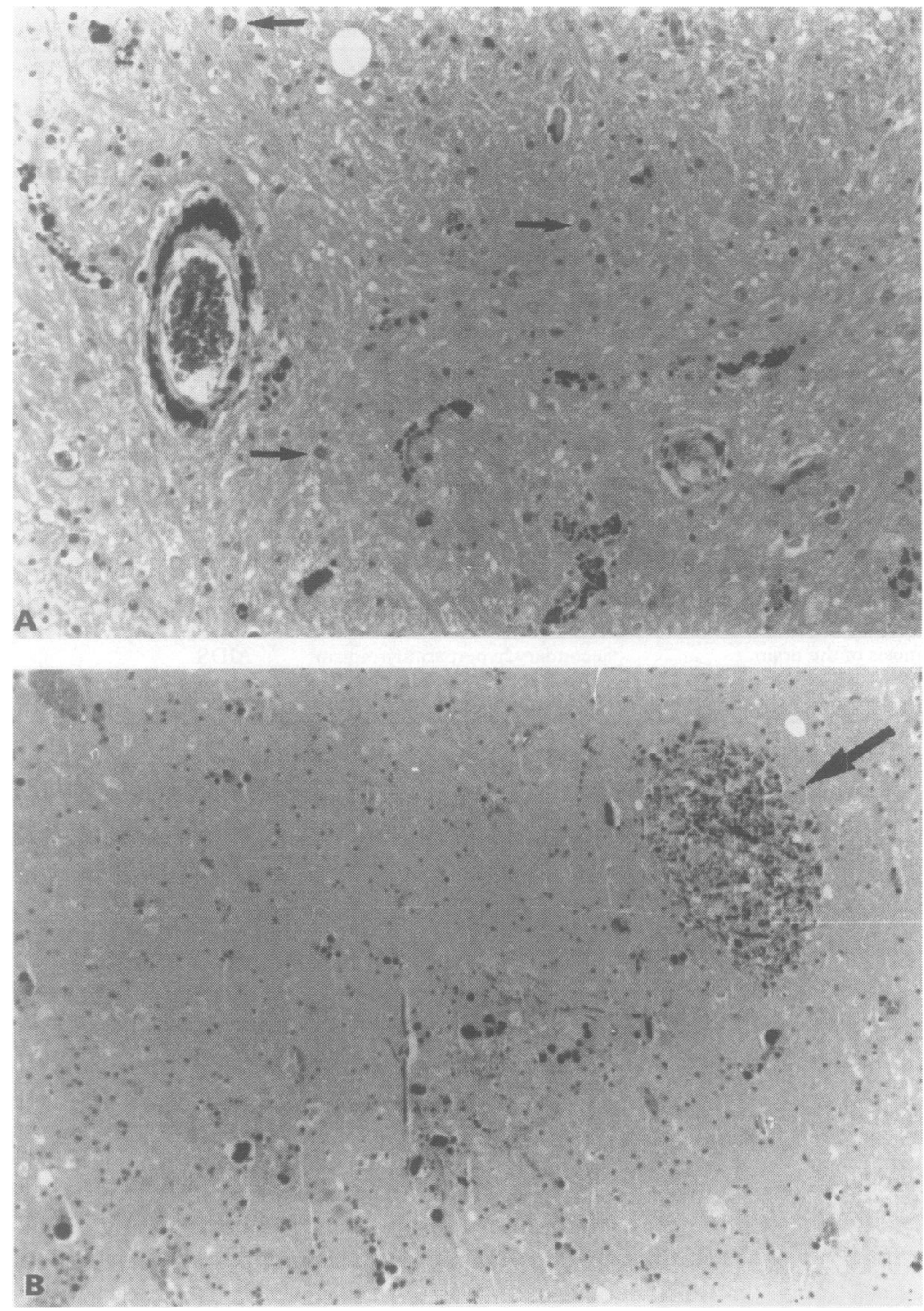

Figure 2 Pathological changes in two cases with AIDS; A) Patient 15. Globus pallidus. Dark mineral deposits can be seen in an arteriolar wall and along the capillaries. Note the presence of large inclusion-bearing oligodentrocytes characteristic of PML (arrows). HEE, $\times 100 ; B)$ Patient 6 . Globus pallidus. Mineralisation of vessel walls and of a focal necrotic lesion (arrow). HE $E, \times 40$.

globus pallidus (fig 2A). Mineralisation was also abundant in the dentate nuclei and was present, but to a much lesser extent, in the cerebral white matter. In the basal ganglia, vascular mineralisation was associated with mild parenchymal changes including widening of the perivascular spaces which contained occasional lipid- or haemosiderinladen macrophages, and a few necrotic foci. In case 6 , mineral deposits were observed in these necrotic lesions (fig 2B).

In case 15 , neuropathological examination also showed limited scar lesions due to toxoplasmosis and confirmed severe changes characteristic of progressive multifocal leucoencephalopathy mainly involving the hemispheric white matter, and also extending to the basal ganglia (fig 2A). A few multinucleated giant cells with cytoplasmic HIV antigens were present. In case 6 , minimal non-specific changes (including granular ependymitis and slight myelin pallor of the hemispheric white matter) were associated with reactive astrocytosis and microglial proliferation. Multinucleated giant cells were present but immunostaining for HIV was negative.

\section{Discussion}

Basal ganglia calcification was found in $2 \%$ of 1478 patients who had CT of the brain during the study period. This prevalence is higher than in previous studies, in which it ranged from $0 \cdot 24 \%^{2}$ to $1 \cdot 64 \%^{3}$ but was generally below $1 \% .^{14-8}$ This discrepancy was not related to the age of the populations, but may have been due to differences in the sensitivity of the CT apparatus used for the study, or to other differences in the populations studied.

Although BGC has been related to many pathological conditions (table 2), several studies led to the conclusion that incidentally detected BGC has no clinical significance. ${ }^{134}$ A surprising finding in our series was the high rate of possible causative or predisposing factors for BGC. However, such results should be interpreted cautiously since, in most instances, a definite causal relationship cannot be demonstrated. For example, it is difficult to determine the influence of carbon monoxide poisoning (case 2) which occurred 30 years before the pallidal calcifications were discovered. However carbon monoxide poisoning is a well-established cause of pallidal vascular calcifications. 9 AIDS appears to be an emerging cause of BGC in young adults. CT detected BGC was first reported in infants and children in this setting, ${ }^{10}$ and rarely in adults. ${ }^{11}$ Interestingly, no calcification was reported in large-scale neuroradiological studies of adults with AIDS. ${ }^{12}$ However, vascular calcifications in the basal ganglia have been described in neuropathological studies. ${ }^{1314}$ The pathogenesis of vascular mineralisation in AIDS is unclear. Mineralisation of vessel walls as a sequel of vasculitis with immune complex deposition in the early stages of HIV infection has been suggested in both children ${ }^{10}$ and adults. ${ }^{15}$ This mechanism could account for the symmetrical pallidal calcifications of three of our four AIDS cases (fig 2A). In another case (29), the pattern of calcifications was clearly different (fig 2B): they were asymmetrical, involved areas other than basal ganglia, and developed within treated toxoplasmic lesions.

Another surprising finding was the high prevalence of disturbances in phosphate/calcium metabolism (8/28 patients). Similar

Table 2 Main conditions associated with symmetrical basal ganglia calcifications in adulthood

Primary and postoperative hypoparathyroidism ${ }^{19}$ Pseudo hypoparathyroidism ${ }^{20}$ Hyperparathyroidism ${ }^{17}$

Carbon monoxide poisoning ${ }^{9}$

CNS infections, ${ }^{18}$ including AIDS ${ }^{14}$

Down's syndrome ${ }^{21}$

Systemic lupus erythematosus ${ }^{22}$

Mitochondrial cytopathy ${ }^{23}$

Chronic lead exposure

Radiation therapys

Familial idiopathic cerebral calcifications ${ }^{25}$ 
results have been reported in only two other studies $^{216}$ and were related to hypoparathyroidism. In our study, these abnormalities suggested hypoparathyroidism in only one case. Their direct responsibility in the onset of BGC is doubtful, except in the case of primary hyperparathyroidism. ${ }^{17}$ The four AIDS patients in our study also had abnormal serum phosphate and/or calcium levels. Two had hyperparathyroidism secondary to renal failure, a condition not known to cause BGC. It is possible, however, that these abnormalities acted as cofactors with local inflammatory changes. Such a mechanism (that is the concurrence of systemic and local factors) has been suggested by Morgante et al. ${ }^{18}$ Moreover, in a study by Muenter and Whisnant, ${ }^{19}$ three patients had hypoparathyroidism and a history of anoxia or encephalitis.

In conclusion, whatever the age of the patient, CT-detected pallidal calcifications should not be considered as "physiological" before a thorough clinical investigation and calcium/phosphate levels are shown to be normal. AIDS is a recently identified cause of BGC and should be borne in mind, particularly in cases involving young adults.

We thank Mrs Line Bazeille and Gisèle Corcket for technical assistance and Mrs Sonia Céva for preparing the manuscript.

1 Cohen CR, Duchesneau PM, Weinstein MA. Calcification of the basal ganglia as visualized by computed tomography. Radiology 1980;134:97-99.

2 Selekler K. Calcification of the basal ganglia on computed tomography. Schweiz Arch Neurol Neurochir Psychiatr 1982;131:187-95

3 Vles JSH, Lodder J, Van der Lugt PJM. Clinical significance of basal ganglia calcifications detected by CT (a retrospective study of 33 cases). Clin Neurol Neurosur 1981;83:253-6.

4 Koller WC, Cochran JW, Klawans HL. Calcification of the basal ganglia: computerized tomography and clinical correlation. Neurology 1979;29:328-33.

5 Murphy MJ. Clinical correlations of CT Scan detected calcifications of the basal ganglia. Ann Neurol 1979;6: 507-11.
6 Sachs C, Ericson K, Erasmie U, Bergström M. Incidence of basal ganglia calcifications on computed tomography. f Comput Assist Tomogr 1979;3:339-44.

7 Brannan TS, Burger AA, Chaudhary MY. Bilateral basal ganglia calcifications visualised on CT scan. $\mathcal{F}$ Neurol Neurosurg Psychiatry 1980;43:403-6.

8 Neurosurg Psychiatry 1980,43.4 Allam BF, Bone I. The significance of the incidental finding of basal ganglia calcification on computed tomography. $\mathcal{f}$ Neurol Neurosurg Psychiatry 1981;44:1168-70.

9 Lapresle J, Fardeau M. The central nervous system and carbon monoxide poisoning II. Anatomical study of brain lesions following intoxication with carbon monoxide (22 cases). In: Bour H, Ledingham IMA, eds. Carbon monoxide poisoning. Progress in brain research, vol 24. Amsterdam: Elsevier, 1967.

10 Belman AL, Lantos G, Horoupian D, et al. AIDS: calcifications of the basal ganglia in infants and children. Neurology 1986;36:1192-9.

11 Belman AL, Lantos G, Horoupian D, Novick B, Wisnia A, Ultmane $M$. Basal ganlionic calcifications in patients with AIDS. Neurology 1985;35(suppl 1):106.

12 Levy RM, Rosenbloom S, Perrett LV. Neuroradiologic finding in AIDS: a review of 200 cases. AFR 1986; 147:977-83

13 Navia BA, Cho ES, Petito CK, Price RW. The AIDS dementia complex: II. Neuropathology 1986;19:525-35.

14 Gray F, Gherardi R, Keohane C, Favolini M, Sobel A, Poirier J. Pathology of the central nervous system in 40 cases of acquired immune deficiency syndrome (AIDS). Neuropathol Appl Neurobiol 1988;14:365-80.

15 Gray F, Lescs MC, Keohane C, et al. Early brain changes in HIV infection: neuropathological study of $11 \mathrm{HIV}$ seropositive, non AIDS cases. $\mathcal{F}$ Neuropathol Exp Neurol 1992;51:177-185.

16 Kazis AD. Contribution of CT scan to the diagnosis of Fahr's syndrome. Acta Neurol Scand 1985;71:206-11.

17 Margolin D, Hammerstad J, Orwoll E, McClung $M$, Calhoun D. Intracranial calcification in hyperparathyroidism associated with gait apraxia and parkinsonism. Neurology 1980;30:1005-7.

18 Morgante L, Vita G, Meduri M, et al. Fahr's syndrome: local inflammatory factors in the pathogenesis of calcification. $\mathcal{F}$ Neurol 1986;233:19-22.

19 Muenter MD, Whisnant JP. Basal ganglia calcification, hypoparathyroidism and extrapyramidal motor manifestations. Neurology 1968;18:1075-83.

20 Illum F, Dupont E. Prevalences of CT detected calcification in the basal ganglia in idiopathic hypoparathyton in the basal ganglia in idiopathic hypoparathyroidism and pse

21 Takashima S, Becker LE. Basal ganglia calcifications in Down's syndrome. F Neurol Neurosurg Psychiatry 1985; 48:61-64.

22 Nordstrom DM, West SG, Andersen PA. Basal ganglia calcifications in central nervous system lupus erythematosus. Arthritis Rheum 1985;28:1412-16.

23 Petty RKH, Harding AE, Morgan-Hughes JA. The clinical features of mitochondrial myopathy. Brain 1986; 109:915-38

24 Reyes PF, Gonzalez CF, Zalewska MK, Besarab A. Intracranial calcification in adults with chronic lead exposure. $A f R$ 1986;146:267-70.

25 Moskowitz MA, Winickoff RN, Heinz ER. Familial calcification of the basal ganglions. New Engl $f$ Med 1971;285:72-7. 